\title{
Treponema berlinense sp. nov. and Treponema porcinum sp. nov., novel spirochaetes isolated from porcine faeces
}

\author{
Correspondence \\ Marcel Nordhoff \\ nordhoff.marcel@vetmed.fu- \\ berlin.de
}

\author{
Marcel Nordhoff, ${ }^{1}$ David Taras, ${ }^{2}$ Moritz Macha, ${ }^{2}$ Karsten Tedin, ${ }^{1}$ \\ Hans-Jürgen Busse ${ }^{3}$ and Lothar $\mathrm{H}$. Wieler ${ }^{1}$ \\ ${ }^{1}$ Institut für Mikrobiologie und Tierseuchen, Freie Universität Berlin, D-10115 Berlin, Germany \\ ${ }^{2}$ Institut für Tierernährung, Freie Universität Berlin, D-10115 Berlin, Germany \\ ${ }^{3}$ Institut für Bakteriologie, Mykologie und Hygiene, Veterinärmedizinische Universität, A-1210 \\ Wien, Austria
}

\begin{abstract}
Limit-dilution procedures were used to isolate seven, helically coiled bacterial strains from faeces of swine that constituted two unidentified taxa. Comparative 16S rRNA gene sequence analysis showed highest similarity values with species of the genus Treponema indicating that the isolates are members of this genus. Strain $7 \mathrm{CPL} 208^{\top}$, as well as five further isolates, and $14 \mathrm{~V} 28^{\top}$ displayed the highest $16 \mathrm{~S}$ rRNA gene sequence similarities with Treponema pectinovorum ATCC $33768^{\top}(92 \cdot 3 \%)$ and Treponema parvum OMZ $833^{\top}(89.9 \%)$, respectively. Polar lipid profiles distinguished $7 \mathrm{CPL} 208^{\top}$ and $14 \mathrm{~V} 28^{\top}$ from each other as well as from related species. Based on their phenotypic and genotypic distinctiveness, strains $7 \mathrm{CPL} 208^{\top}$ and $14 \mathrm{~V} 28^{\top}$ are suggested to represent two novel species of the genus Treponema, for which the names Treponema berlinense sp. nov. and Treponema porcinum sp. nov. are proposed. The type strain for Treponema berlinense is 7CPL208 ${ }^{\top}\left(=\right.$ ATCC BAA-909 $^{\top}=$ CIP $\left.108244^{\top}=J C M 12341^{\top}\right)$ and for Treponema porcinum $14 \mathrm{~V}^{2} 8^{\top}\left(=\mathrm{ATCC}^{\mathrm{BAA}}-908^{\top}=\mathrm{CIP} 108245^{\top}=\mathrm{JCM} 12342^{\top}\right)$.
\end{abstract}

Due to difficulties in the culture of Treponema species, only a small number have been cultivated (Sakamoto et al., 1999; Siqueira \& Rocas, 2003). As a result, most oral Treponema species have been identified only by their 16S rRNA gene sequences (Dewhirst et al., 2000). In the gastrointestinal tract of termites, comparative $16 \mathrm{~S}$ rRNA gene sequence analyses have revealed more than 67 different treponemal phylotypes (Lilburn et al., 1999) of which only two distinct species have been isolated and characterized (Lilburn et al., 2001; Graber et al., 2004). Recent improvements in cultivation techniques have resulted in the identification and characterization of several novel Treponema species (Smibert \& Burmeister, 1983; Umemoto et al., 1997; Schrank et al., 1999; Wyss et al., 1996, 1997, 1999, 2001, 2004). In the gastrointestinal tract of animals, Treponema bryantii and Treponema saccharophilum have been cultivated from the rumen of cows (Stanton \& Canale-Parola, 1980; Paster \& Canale-Parola, 1985). Although the presence

The GenBank/EMBL/DDBJ accession numbers for the 16S rRNA gene sequences of Treponema berlinense strain $7 C P L 208^{\top}$ and Treponema porcinum strain $14 \mathrm{~V} 28^{\top}$ are AY230217 and AY518274, respectively.

Transmission electron micrographs, SDS-PAGE analyses, genomic fingerprinting gels and polar lipid profiles are available as supplementary material in IJSEM Online. of Treponema-related spirochaetes in swine intestine and faeces has been reported (Smibert \& Claterbaugh, 1972; Livermore \& Johnson, 1975), only one species, Treponema succinifaciens, has been isolated and described in swine (Cwyk \& Canale-Parola, 1979).

As part of a study on the microbial diversity of the gastrointestinal tract of swine, strains $7 \mathrm{CPL} 208^{\mathrm{T}}$, 11IV56, 25AKT66, 27VII56, 33AKL503, 13VII56 and $14 \mathrm{~V}_{2} 8^{\mathrm{T}}$ were recovered from faeces. Faeces were suspended in OMIZ-Pat medium supplemented with $10 \%(\mathrm{v} / \mathrm{v})$ brain heart infusion $(\mathrm{BHI}), 10 \%(\mathrm{v} / \mathrm{v})$ trypticase soy yeast extract (TSYE), rifampicin $\left(1 \mu \mathrm{g} \mathrm{ml}^{-1}\right)$ and phosphomycin $\left(100 \mu \mathrm{g} \mathrm{ml}^{-1}\right)$ using limit-dilution procedures and were incubated anaerobically for 3-4 days at $37^{\circ} \mathrm{C}$ (Wyss, 1992; Wyss et al., 1996). When spirochaete bacteria were visible by dark-field microscopy, subcultures were performed on supplemented OMIZ-Pat agar plates $(1 \cdot 3 \% \mathrm{w} / \mathrm{v})$. To obtain pure cultures, single colonies were purified from agar plates and transferred to liquid medium for further analyses. Agar plates were supplemented with $5 \%(\mathrm{v} / \mathrm{v})$ sheep blood for strain $7 \mathrm{CPL} 208^{\mathrm{T}}$ and with $5 \%(\mathrm{v} / \mathrm{v})$ egg yolk for strain $14 \mathrm{~V} 28^{\mathrm{T}}$.

Cell morphology was examined by transmission electron microscopy as described previously (Cwyk \& Canale-Parola, 1979). Cells showed typical spirochaete morphology, 
exhibiting two to three windings and two subterminally inserted flagella (see Supplementary Fig. S1 available in IJSEM Online).

Genomic DNA was purified as described by Schrank et al. (1999). Amplified PCR products were sequenced commercially (MWG Biotech). Phylogenetic analyses were performed using the software package DNASTAR for multiple alignment of sequences and MEGA (Kimura et al., 1993). Distances (distance options according to the Kimura two-parameter model) and clustering with the neighbourjoining method were determined using bootstrap values based on 1000 reiterations.

Continuous 16S rRNA gene sequences of 1450 and $1500 \mathrm{bp}$ were obtained for strains $7 \mathrm{CPL} 208^{\mathrm{T}}$ and $14 \mathrm{~V} 28^{\mathrm{T}}$, respectively, and partial $16 \mathrm{~S}$ rRNA gene sequences of about $650 \mathrm{bp}$ (data not shown) were obtained from 11IV56, 25AKT66, 27VII56, 33AKL503 and 13VII56. Partial 16S rRNA gene sequences of 11IV56, 25AKT66, 27VII56, 33AKL503 and 13 VII56 were identical to the corresponding 16S rRNA gene sequence of $7 \mathrm{CPL} 208^{\mathrm{T}}$, indicating a possible relationship at the species level. Sequence similarities indicated that the closest relatives of strains $7 \mathrm{CPL} 208^{\mathrm{T}}$ and $14 \mathrm{~V} 28^{\mathrm{T}}$ were Treponema pectinovorum ATCC $33768^{\mathrm{T}}(92 \cdot 3 \%)$ and Treponema parvum OMZ $833^{\mathrm{T}}(89.9 \%)$, respectively. Strains $7 \mathrm{CPL} 208^{\mathrm{T}}$ and $14 \mathrm{~V} 28^{\mathrm{T}}$ shared sequence similarities of $89 \cdot 2 \%$.

Phylogenetic calculations after neighbour-joining analyses confirmed these relationships (Fig. 1). Strain 7 CPL $208^{\mathrm{T}}$ was placed in group 8 of the oral treponemes, of which $T$. pectinovorum ATCC $33768^{\mathrm{T}}$ is so far the only representative (Dewhirst et al., 2000). Strain $14 \mathrm{~V} 28^{\mathrm{T}}$ could not be assigned to any of these groups.

Culture characteristics were examined using either glucuronic or galacturonic acid supplementation of carbohydrate-free OMIZ-Pat medium. In both cases, growth was observed for strain $7 \mathrm{CPL} 208^{\mathrm{T}}$ and related isolates. In carbohydrate-supplemented OMIZ-Pat medium without the addition of glucuronic and galacturonic acid, growth was observed for strain $14 \mathrm{~V} 28^{\mathrm{T}}$. In contrast, $T$. parvum required supplementation with at least one of these substances (Wyss et al., 2001).

For strain $7 \mathrm{CPL} 208^{\mathrm{T}}$ and related isolates, no visible growth was observed in glucuronic and galacturonic acid-free medium, with one exception, strain 25AKT66, which showed only a decreased growth rate. These results indicated that addition of either glucuronic or galacturonic acid promoted growth of $7 \mathrm{CPL} 208^{\mathrm{T}}$ and related isolates, as previously described for T. pectinovorum (Smibert \& Burmeister, 1983). In contrast to $T$. pectinovorum, no growth was observed for either strain with pectin as the sole carbon source.

The ability to use a single carbohydrate source was investigated by the addition of one of the following compounds to carbohydrate-free OMIZ-Pat medium containing galacturonic and glucuronic acid: D-glucose, D-fructose, D-maltose, D-mannitol, D-mannose, D-arabinose, L-fucose, D-trehalose, D-sucrose or L-rhamnose. For isolate $14 \mathrm{~V} 28^{\mathrm{T}}$, growth was only observed in presence of D-maltose, whereas the growth rate of 7 CPL208 ${ }^{\mathrm{T}}$ was enhanced by the addition of any one of these carbohydrates to OMIZ-Pat medium.

Enzyme profiles were determined using the API ZYM and Rapid ID 32A systems (bioMérieux) according to the manufacturer's instructions. Using the Rapid ID 32A system, isolate $14 \mathrm{~V} 28^{\mathrm{T}}$ showed a positive reaction only for $\alpha$-glucosidase, which was also consistent with the results from the API ZYM system. Strain 7 CPL $208^{\mathrm{T}}$ was negative

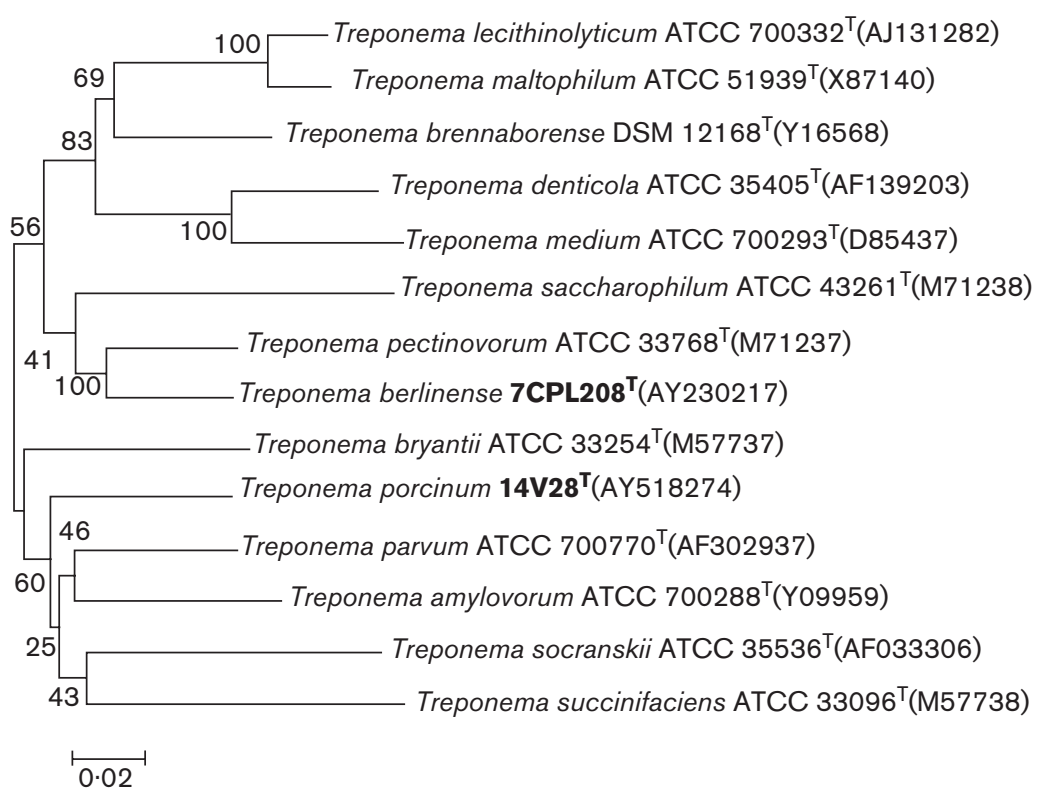

Fig. 1. Phylogenetic analysis based on $16 \mathrm{~S}$ rRNA gene sequences constructed after multiple alignment of data by CLUSTAL W (accession numbers in parentheses). Distances were calculated (distance options according to the Kimura-2 model) and clustering with the neighbour-joining method was performed using the software package MEGA version 2.1. 
for all enzyme reactions tested. Identical profiles were obtained for 7 CPL208 ${ }^{\mathrm{T}}$, 11IV56, 25AKT66, 27VII56, 33 AKL503 and 13VII56 using the API ZYM system and these profiles clearly distinguished them from $14 \mathrm{~V} 28^{\mathrm{T}}$ and other closely related Treponema species previously examined by this method (Table 1). The detailed enzyme profiles are indicated in the species descriptions.

In order to examine relationships at the species level, 7CPL208 ${ }^{\mathrm{T}}$, 11IV56, 25AKT66, 27VII56, 33AKL503 and 13 VII56 were compared with each other and with $14 \mathrm{~V} 28^{\mathrm{T}}$ by SDS-PAGE of whole-cell protein patterns and genomic fingerprinting analyses using RAPD- and ERIC-PCR. SDSPAGE of whole-cell proteins using standard protocols (Sambrook et al., 1989) showed essentially identical protein profiles for these related isolates (see Supplementary Fig. S2 in IJSEM Online). Genomic fingerprinting was performed by both RAPD- and ERIC-PCR. The RAPD-PCR utilized $1.5 \mathrm{mM} \mathrm{MgCl}_{2}, 0.2 \mathrm{mM} \mathrm{dNTPs,} 12.5$ pmol primer (random primer $5^{\prime}$-GCGGCTGGAG-3'), $100 \mathrm{ng}$ genomic DNA and reaction buffer supplied by the manufacturer (Rapidozym) in a total volume of $50 \mu \mathrm{l}$. Samples were

Table 1. Biochemical characteristics of type strains of Treponema species as described using the API ZYM system

Species: 1, 'Treponema vincentii' ATCC 35580 (data from Schrank et al., 1999); 2, T. denticola 51B2 (Schrank et al., 1999); 3, T. brennaborense DSM $12168^{\mathrm{T}}$ (Schrank et al., 1999); 4, T. maltophilum ATCC $51939^{\mathrm{T}}$ (Wyss et al., 1996); 5, T. amylovorum ATCC $700288^{\mathrm{T}}$ (Wyss et al., 1996); 6, T. pectinovorum ATCC $33768^{\mathrm{T}}$ (Schrank et al., 1999); 7, T. socranskii sub sp. socranski ATCC $35536^{\mathrm{T}}$ (Schrank et al., 1999); 8. T. parvum ATCC $700770^{\mathrm{T}}$ (Wyss et al., 2001); 9, T. lecithinolyticum ATCC $700332^{\mathrm{T}}$ (Wyss et al., 1999); 10, T. berlinense sp. nov. (six isolates); 11, T. porcinum sp. nov. $14 \mathrm{~V} 28^{\mathrm{T}}$. All strains are positive for acid phosphatase and naphthol-AS-BI-phosphohydrolase and negative for lipase (C14), valine arylamidase and $\alpha$-mannosidase. + , Positive; - , negative; $(+)$, weakly positive.

\begin{tabular}{|c|c|c|c|c|c|c|c|c|c|c|c|}
\hline Characteristic & 1 & 2 & 3 & 4 & 5 & 6 & 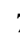 & & 8 & 9 & \\
\hline Alkaline phosphatase & - & + & + & + & $t$ & & & & $+(+)$ & + & \\
\hline Esterase (C4) & - & + & + & + & + & $t$ & - & & +1 & + & - \\
\hline Esterase lipase (C8) & - & + & + & + & - & $t$ & & & $(+)$ & + & - \\
\hline Leucine arylamidase & + & + & - & - & - & - & - & & - & - & - \\
\hline Cystine arylamidase & - & + & - & - & - & - & - & & - & - & \\
\hline Trypsin & - & + & - & - & - & - & - & & - & - & \\
\hline$\alpha$-Chymotrypsin & - & + & - & - & - & 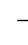 & - & & - & - & \\
\hline$\alpha$-Galactosidase & - & + & - & + & - & - & - & & - & - & - \\
\hline$\beta$-Galactosidase & + & + & T & - & & & & & + & + & \\
\hline$\beta$-Glucuronidase & - & - & - & - & . & & & & - & + & - \\
\hline$\alpha$-Glucosidase & - & - & t & + & & & & & - & - & - \\
\hline$\beta$-Glucosidase & - & + & - & - & & & & & - & - & \\
\hline$N$-Acetyl- $\beta$-glucosaminidase & + & - & + & - & - & & & & - & + & - \\
\hline$\alpha$-Fucosidase & - & - & & 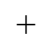 & & & & & - & + & - \\
\hline
\end{tabular}

preheated at $94{ }^{\circ} \mathrm{C}$ for $5 \mathrm{~min}$ followed by amplification with $94^{\circ} \mathrm{C}$ for $30 \mathrm{~s}, 40^{\circ} \mathrm{C}$ for $30 \mathrm{~s}$ and $72^{\circ} \mathrm{C}$ for $45 \mathrm{~s}$. A total of 45 cycles was carried out with a final elongation step at $72{ }^{\circ} \mathrm{C}$ for $10 \mathrm{~min}$. ERIC-PCR using primers ERIC-1R $\left(5^{\prime}\right.$-ATGTAAGCTCCTGGGGATTCAC- $\left.{ }^{\prime}\right)$ and ERIC-2 (5'-AAGTAAGTGACTGGGGTGAGCG-3') was conducted in $50 \mu \mathrm{l}$ containing $2 \mathrm{mM} \mathrm{MgCl}_{2}, 0.2 \mathrm{mM}$ dNTPs, $12.5 \mathrm{pmol}$ primer and $50 \mathrm{ng}$ genomic DNA. Samples were preheated at $94^{\circ} \mathrm{C}$ for $5 \mathrm{~min}$ followed by amplification with $94{ }^{\circ} \mathrm{C}$ for $30 \mathrm{~s}, 46^{\circ} \mathrm{C}$ for $5 \mathrm{~min}$ and $72^{\circ} \mathrm{C}$ for $5 \mathrm{~min}$. A total of 45 cycles was carried out with a final elongation step at $72{ }^{\circ} \mathrm{C}$ for $10 \mathrm{~min}$. The RAPD fingerprints of $7 \mathrm{CPL} 208^{\mathrm{T}}$, 11IV56, 25AKT66, 27VII56, 33AKL503 and 13VII56 shared at least two major bands at approximately 550 and $1050 \mathrm{bp}$. Several shared bands were present in the ERIC fingerprints, with one major band at approximately $1200 \mathrm{bp}$ as determined by gel electrophoresis. These fingerprints also distinguished this group of isolates from $14 \mathrm{~V} 28^{\mathrm{T}}$ and other related Treponema species (Supplementary Fig. S3 in IJSEM Online). Strain 25AKT66 was unique among this set of isolates as indicated by slightly different growth characteristics and slightly varying protein and genomic fingerprint patterns.

Although several reports have been published on the presence and variability of polar lipids in Treponema species (Livermore \& Johnson, 1974; Matthews et al., 1979), polar lipid profiles have not been introduced into their classification. These early studies prompted us to apply this approach to the classification of strain $7 \mathrm{CPL} 208^{\mathrm{T}}$ and $14 \mathrm{~V} 28^{\mathrm{T}}$. For analysis of the polar lipid profiles, strains 7 CPL $208^{\mathrm{T}}$, $14 \mathrm{~V} 28^{\mathrm{T}}$, Treponema socranskii ATCC $3553^{\mathrm{T}}$ and T. pectinovorum ATCC $33768^{\mathrm{T}}$ were grown in supplemented OMIZ-Pat medium at $37^{\circ} \mathrm{C}$ under anaerobic conditions. Analysis of their polar lipids (Tindall, 1990; Altenburger et al., 1997) revealed a unique, complex profile for each strain (Supplementary Fig. S4 in IJSEM Online), further demonstrating that strains $7 \mathrm{CPL} 208^{\mathrm{T}}$ and $14 \mathrm{~V} 28^{\mathrm{T}}$ represented novel species of the genus Treponema. Strain 7 CPL $208^{\mathrm{T}}$ displayed a polar lipid profile consisting of the major compounds diphosphatidylglycerol, phosphatidylethanolamine, an unknown aminophospholipid and an unknown, highly hydrophobic compound. Moderate or minor amounts of phosphatidylglycerol, several unknown aminophospholipids, phospholipids, aminolipids, polar lipids and a glycolipid were also present. The closest phylogenetic relative of 7CPL208 ${ }^{\mathrm{T}}$, T. pectinovorum ATCC $33768^{\mathrm{T}}$, shared the majority of the major compounds except for the predominant aminophospholipid APL4 and several of the other lipids present in moderate to minor amounts.

In contrast to these two strains, no phosphatidylethanolamine was detected in extracts of $14 \mathrm{~V} 28^{\mathrm{T}}$ or T. socranskii ATCC $33768^{\mathrm{T}}$. Strain $14 \mathrm{~V} 28^{\mathrm{T}}$ displayed a polar lipid profile consisting mainly of phospholipids, including diphosphatidylglycerol and phosphatidylglycerol, glycolipid GL1 and some unknown polar lipids, but completely lacking aminolipids (Supplementary Fig. S4c in IJSEM Online). The 
major lipids present were three unknown phospholipids (PL1, PL14 and PL15) and an unknown, highly hydrophobic lipid, L1. T. socranskii ATCC $33768^{\mathrm{T}}$ and strain $14 \mathrm{~V} 28^{\mathrm{T}}$ both contained ten phospholipids, glycolipid GL1 and unknown lipid L1. An unknown aminophospholipid, APL1, and two unknown aminolipids, AL1 and AL2, were also found in the profile of T. socranskii ATCC $33768^{\mathrm{T}}$ (Supplementary Fig. S4d in IJSEM Online). Major compounds were diphosphatidylglycerol, phosphatidylglycerol, unknown phospholipid PL5 and unknown lipid L1.

A comparison of the polar lipid profiles of the four strains analysed indicated a higher degree of similarity between the strains of the close phylogenetic relative pairs 7 CPL $208^{\mathrm{T}} /$ T. pectinovorum ATCC $33768^{\mathrm{T}}$ and $14 \mathrm{~V} 28^{\mathrm{T}} /$ T. socranskii ATCC $33768^{\mathrm{T}}$ than between strains of different pairs. Our data indicate that analysis of polar lipids is a useful approach for the characterization and differentiation of Treponema strains. This conclusion is supported by the analysis of the polar lipids of two additional species, Treponema denticola ATCC 35521 and Treponema brennaborense DSM $12168^{\mathrm{T}}$, each of which displayed a unique profile (data not shown). These results may also indicate that polar lipid profiles display, to some degree, the phylogenetic relationships within species of the genus Treponema. In the future, such profiles may serve as important markers for the dissection of this genus that might be necessary due to the deep phylogenetic branching of species found within the genus. Identical or near-identical phenotypic and genotypic characteristics indicated that strains $7 \mathrm{CPL} 208^{\mathrm{T}}$, 11IV56, 25AKT66, 27VII56, 33AKL503 and 13VII56 are members of a single species.

Strains 7 CPL208 $8^{\mathrm{T}}$ and $14 \mathrm{~V} 28^{\mathrm{T}}$ were distinguished from related Treponema species by their $16 \mathrm{~S}$ rRNA gene sequences, which exhibited the highest sequence similarities with Treponema pectinovorum ATCC $33768^{\mathrm{T}}(92 \cdot 3 \%)$ and Treponema parvum OMZ $833^{\mathrm{T}}(89 \cdot 9 \%)$, respectively, whereas strains $7 \mathrm{CPL} 208^{\mathrm{T}}$ and $14 \mathrm{~V} 28^{\mathrm{T}}$ shared $89 \cdot 2 \%$ sequence similarity. Using different genomic fingerprinting methods (RAPD- and ERIC-PCR) these strains could be clearly differentiated from related Treponema species by their unique fingerprint patterns. In addition, strains $7 \mathrm{CPL} 208^{\mathrm{T}}$ and $14 \mathrm{~V} 28^{\mathrm{T}}$ differed from other Treponema species in their phenotypic characteristics. In contrast to $T$. pectinovorum ATCC $33768^{\mathrm{T}}$, strain $7 \mathrm{CPL} 208^{\mathrm{T}}$ showed positive enzyme reactions only for acid phosphatase and naphthol-AS-BI-phosphohydrolase and no activity for esterase $\mathrm{C} 4$ or esterase lipase C8. No growth occurred with pectin as the sole carbohydrate source. Unlike Treponema parvum OMZ $833^{\mathrm{T}}$, strain $14 \mathrm{~V} 28^{\mathrm{T}}$ exhibited a positive reaction for $\alpha$-glucosidase but lacked activity for $\beta$-galactosidase, alkaline phosphatase and esterase lipase C8. In addition, while neither glucuronic nor galacturonic acids were essential for growth, D-maltose was required.

These results suggest that strains $7 \mathrm{CPL} 208^{\mathrm{T}}$ and $14 \mathrm{~V} 28^{\mathrm{T}}$ constitute two distinct genomic species that are clearly differentiated from other Treponema species. We therefore propose the names Treponema berlinense sp. nov. and Treponema porcinum sp. nov. for strains $7 \mathrm{CPL} 208^{\mathrm{T}}$ and $14 \mathrm{~V} 28^{\mathrm{T}}$, respectively.

\section{Description of Treponema berlinense sp. nov.}

Treponema berlinense (ber.li.nen'se. N.L. neut. adj. berlinense pertaining to Berlin, Germany, where the type strain was isolated).

Cells show typical spirochaete morphology exhibiting two to three windings with two periplasmic, subterminally inserted flagella. Cells are approximately $6 \mu \mathrm{m}$ in length and $0.3 \mu \mathrm{m}$ in width. Strictly anaerobic. Good growth is observed in liquid OMIZ-Pat medium at $37^{\circ} \mathrm{C}$ supplemented with $10 \%(\mathrm{v} / \mathrm{v}) \mathrm{BHI}$ and $10 \%(\mathrm{v} / \mathrm{v})$ TSYE. On OMIZ-Pat agar plates $(1.3 \% \mathrm{w} / \mathrm{v})$ supplemented with $5 \%(\mathrm{v} / \mathrm{v})$ sheep blood, $10 \%(\mathrm{v} / \mathrm{v})$ BHI and $10 \%(\mathrm{v} / \mathrm{v})$ TSYE, species forms small, irregular, greyish swarms up to $1-2 \mathrm{~mm}$ in diameter, visible after 3-4 days. Addition of galacturonic or glucuronic acid promotes growth, which is enhanced further by addition of any of the following carbohydrates: D-glucose, D-fructose, D-maltose, D-mannitol, Dmannose, D-arabinose, L-fucose, D-trehalose, D-sucrose and L-rhamnose. No visible growth is observed with pectin as the sole carbon source. Using the API ZYM and Rapid ID 32A systems, positive enzyme reactions are obtained only for acid phosphatase and naphtholAS-BI-phosphohydrolase. Negative in tests for alkaline phosphatase, esterase $\mathrm{C} 4$, esterase lipase $\mathrm{C} 8$, leucine arylamidase, cystine arylamidase, trypsin, $\alpha$-chymotrypsin, $\alpha$-galactosidase, $\beta$-galactosidase, $\beta$-glucuronidase, $\alpha$ glucosidase, $\beta$-glucosidase, $N$-acetyl- $\beta$-glucosaminidase, $\alpha$ fucosidase, urease, arginine dihydrolase, $\alpha$-arabinosidase, mannose and raffinose fermentation, glutamic acid decarboxylase, $\alpha$-fucosidase, arginine arylamidase, proline arylamidase, leucyl glycine arylamidase, phenylalanine arylamidase, leucine arylamidase, pyroglutamic acid arylamidase, tyrosine arylamidase, alanine arylamidase, glycine arylamidase, histidine arylamidase, glutamyl glutamic acid arylamidase and serine arylamidase. Reduction of nitrates and indole production are not detected. The polar lipid profile contains diphosphatidylglycerol, phosphatidylethanolamine, an unknown aminophospholipid and an unknown highly hydrophobic compound as major components. Moderate or minor amounts of phosphatidylglycerol, several unknown aminophospholipids, phospholipids, amino lipids, polar lipids and a glycolipid are also present.

The type strain, 7 CPL $208^{\mathrm{T}} \quad\left(\right.$ ATCC BAA $-909^{\mathrm{T}}=\mathrm{CIP}$ $108244^{\mathrm{T}}=\mathrm{JCM} 12341^{\mathrm{T}}$ ), was isolated from swine faeces in Berlin, Germany.

\section{Description of Treponema porcinum sp. nov.}

Treponema porcinum (por.ci'num. L. neut. adj. porcinum pertaining to swine, from which the type strain was isolated). 
Cells exhibit typical spirochaete morphology and are approximately $6-8 \mu \mathrm{m}$ in length and $0.3 \mu \mathrm{m}$ in width with two to three windings. Transmission electron microscopy reveals two periplasmic, subterminally inserted flagella. Strictly anaerobic. Best growth is obtained in liquid OMIZ-Pat medium at $37^{\circ} \mathrm{C}$ supplemented with $10 \%$ $(\mathrm{v} / \mathrm{v})$ BHI and $10 \%(\mathrm{v} / \mathrm{v})$ TSYE. Growth is independent of glucuronic or galacturonic acid. D-Maltose is essential for growth, whereas no growth is observed in the presence of any of the following carbohydrates as the sole carbohydrate source: D-glucose, D-fructose, D-mannitol, Dmannose, D-arabinose, L-fucose, D-trehalose, D-sucrose and L-rhamnose. Does not grow with pectin as a sole carbon source. On supplemented OMIZ-Pat $(1 \cdot 3 \% \mathrm{w} / \mathrm{v})$ agar supplemented with $5 \%$ egg yolk, $10 \% \mathrm{BHI}$ and $10 \%$ TSYE, the species forms small, greyish, irregular swarms up to $2 \mathrm{~mm}$ in diameter, visible after 3-4 days. Positive enzyme reactions using the API ZYM and Rapid ID 32A system are obtained for acid phosphatase, esterase $\mathrm{C} 4$, naphtholAS-BI-phosphohydrolase and $\alpha$-glucosidase, whereas reactions for alkaline phosphatase, esterase lipase C8, leucine arylamidase, cystine arylamidase, trypsin, $\alpha$-chymotrypsin, $\alpha$-galactosidase, $\beta$-galactosidase, $\beta$-glucuronidase, $\beta$ glucosidase, $\quad N$-acetyl- $\beta$-glucosaminidase, $\alpha$-fucosidase, urease, arginine dihydrolase, $\alpha$-arabinosidase, mannose and raffinose fermentation, glutamic acid decarboxylase, $\alpha$-fucosidase, arginine arylamidase, proline arylamidase, leucyl glycine arylamidase, phenylalanine arylamidase, leucine arylamidase, pyroglutamic acid arylamidase, tyrosine arylamidase, alanine arylamidase, glycine arylamidase, histidine arylamidase, glutamyl glutamic acid arylamidase and serine arylamidase are negative. Reduction of nitrates and indole production are not detected. In the polar lipid profile, three unknown phospholipids and a highly hydrophobic compound predominate. Diphosphatidylglycerol, phosphatidylglycerol as well as phospholipids are present in moderate amounts. Additionally, a glycolipid and several phospholipids are present in minor amounts.

The type strain, $14 \mathrm{~V} 28^{\mathrm{T}}$ (deposited as ATCC BAA$908^{\mathrm{T}}=$ CIP $\left.108245^{\mathrm{T}}=\mathrm{JCM} 12342^{\mathrm{T}}\right)$, was isolated from swine faeces in Berlin, Germany.

\section{Acknowledgements}

We thank Professor Dr Hans G. Trüper for his advice on etymology and Michael Riess for assistance with the electron microscopy studies. This work was supported by the Deutsche Forschungsgemeinschaft Grant FOR 438/1-1.

\section{References}

Altenburger, P., Kämpfer, P., Akimov, V. N., Lubitz, W. \& Busse, H.-J. (1997). Polyamine distribution in actinomycetes with Group $B$ peptidoglycan and species of the genera Brevibacterium, Corynebacterium, and Tsukamurella. Int J Syst Bacteriol 47, 270-277.

Cwyk, W. M. \& Canale-Parola, E. (1979). Treponema succinifaciens sp. nov., an anaerobic spirochete from the swine intestine. Arch Microbiol 122, 231-239.
Dewhirst, F. E., Tamer, M. A., Ericson, R. E., Lau, C. N., Levanos, V. A., Boches, S. K., Galvin, J. L. \& Paster, B. J. (2000). The diversity of periodontal spirochetes by $16 \mathrm{~S}$ rRNA analysis. Oral Microbiol Immunol 15, 196-202.

Graber, J. R., Leadbetter, J. R. \& Breznak, J. A. (2004). Description of Treponema azotonutricium sp. nov. and Treponema primitia sp. nov., the first spirochetes isolated from termite guts. Appl Environ Microbiol 70, 1315-1320.

Kimura, Y., Takahashi, M., Matsumoto, N. \& 8 other authors (1993). Verrucose dermatitis and digital papillomatosis in dairy cows. $J$ Vet Med Jpn 46, 899-906.

Lilburn, T. G., Schmidt, T. M. \& Breznak, J. A. (1999). Phylogenetic diversity of termite gut spirochaetes. Environ Microbiol 1, 331-345.

Lilburn, T. G., Kim, K. S., Ostrom, N. E., Byzek, K. R., Leadbetter, J. R. \& Breznak, J. A. (2001). Nitrogen fixation by symbiotic and free-living spirochetes. Science 292, 2495-2498.

Livermore, B. P. \& Johnson, R. C. (1974). Lipids of the Spirochaetales: comparison of the lipids of several members of the genera Spirochaeta, Treponema, and Leptospira. J Bacteriol 120, 1268-1273.

Livermore, B. P. \& Johnson, R. C. (1975). The lipids of four unusual non-pathogenic host-associated spirochetes. Can J Microbiol 21, 1877-1880.

Matthews, H. M., Yang, T.-K. \& Jenkin, H. M. (1979). Unique lipid composition of Treponema pallidum (Nichols virulent strain). Infect Immun 24, 713-719.

Paster, B. J. \& Canale-Parola, E. (1985). Treponema saccharophilum sp. nov., a large pectinolytic spirochete from the bovine rumen. Appl Environ Microbiol 50, 212-219.

Sakamoto, M., Takeuchi, Y., Umeda, M., Ishikawa, I., Benno, Y. \& Nakase, T. (1999). Detection of Treponema socranskii associated with human periodontitis by PCR. Microbiol Immunol 43, 485-490.

Sambrook, J., Fritsch, E. F. \& Maniatis, T. (1989). Molecular Cloning: a Laboratory Manual, 2nd edn. Cold Spring Harbor, NY: Cold Spring Harbor Laboratory.

Schrank, K., Choi, B. K., Grund, S., Moter, A., Heuner, K., Nattermann, H. \& Gobel, U. B. (1999). Treponema brennaborense sp. nov., a novel spirochaete isolated from a dairy cow suffering from digital dermatitis. Int J Syst Bacteriol 49, 43-50.

Siqueira, J. F. \& Rocas, I. N. (2003). PCR-based identification of Treponema maltophilum, T. amylovorum, T. medium, and $T$. lecithinolyticum in primary root canal infections. Arch Oral Biol 48, 495-502.

Smibert, R. M. \& Burmeister, J. A. (1983). Treponema pectinovorum sp. nov. isolated from humans with periodontitis. Int J Syst Bacteriol 33, 852-856.

Smibert, R. M. \& Claterbaugh, R. L., Jr (1972). A chemically defined medium for Treponema strain PR-7 isolated from the intestine of a pig with swine dysentery. Can J Microbiol 18, 1073-1078.

Stanton, T. B. \& Canale-Parola, E. (1980). Treponema bryantii sp. nov., a rumen spirochete that interacts with cellulolytic bacteria. Arch Microbiol 127, 145-156.

Tindall, B. J. (1990). Lipid composition of Halobacterium lacusprofundi. FEMS Microbiol Lett 66, 199-202.

Umemoto, T., Nakazawa, F., Hoshino, E., Okada, K., Fukunaga, M. \& Namikawa, I. (1997). Treponema medium sp. nov., isolated from human subgingival dental plaque. Int J Syst Bacteriol 47, 67-72.

Wyss, C. (1992). Growth of Porphyromonas gingivalis, Treponema denticola, $T$. pectinovorum, $T$. socranskii, and $T$. vincentii in a chemically defined medium. J Clin Microbiol 30, 2225-2229. 
Wyss, C., Choi, B. K., Schupbach, P., Guggenheim, B. \& Gobel, U. B. (1996). Treponema maltophilum sp. nov., a small oral spirochete isolated from human periodontal lesions. Int J Syst Bacteriol 46, 745-752.

Wyss, C., Choi, B. K., Schupbach, P., Guggenheim, B. \& Gobel, U. B. (1997). Treponema amylovorum sp. nov., a saccharolytic spirochete of medium size isolated from an advanced human periodontal lesion. Int J Syst Bacteriol 47, 842-845.

Wyss, C., Choi, B. K., Schupbach, P., Moter, A., Guggenheim, B. \& Gobel, U. B. (1999). Treponema lecithinolyticum sp. nov., a small saccharolytic spirochaete with phospholipase A and C activities associated with periodontal diseases. Int J Syst Bacteriol 49, 1329-1339.
Wyss, C., Dewhirst, F. E., Gmur, R., Thurnheer, T., Xue, Y., Schupbach, P., Guggenheim, B. \& Paster, B. J. (2001). Treponema parvum sp. nov., a small, glucuronic or galacturonic acid-dependent oral spirochaete from lesions of human periodontitis and acute necrotizing ulcerative gingivitis. Int J Syst Evol Microbiol 51, 955-962.

Wyss, C., Moter, A., Choi, B. K., Dewhirst, F. E., Xue, Y., Schupbach, P., Gobel, U. B., Paster, B. J. \& Guggenheim, B. (2004). Treponema putidum sp. nov., a medium-sized proteolytic spirochaete isolated from lesions of human periodontitis and acute necrotizing ulcerative gingivitis. Int J Syst Evol Microbiol 54, 1117-1122. 